Ionic liquids affect the adsorption of liposomes onto cationic polyelectrolyte coated silica evidenced by quartz crystal microbalance

\title{
Dusa, Filip
}

2015-09-28

Dusa, F , Ruokonen, S-K , Petrovaj , J , Viitala , T J S \& Wiedmer , S K 2015 , ' Ionic liquids affect the adsorption of liposomes onto cationic polyelectrolyte coated silica evidenced by quartz crystal microbalance ' , Colloids and Surfaces B: Biointerfaces , vol. 136 , pp. 496-505 . https://doi.org/10.1016/j.colsurfb.2015.09.059

http://hdl.handle.net/10138/229023

https://doi.org/10.1016/j.colsurfb.2015.09.059

cc_by_nc_nd

acceptedVersion

Downloaded from Helda, University of Helsinki institutional repository.

This is an electronic reprint of the original article.

This reprint may differ from the original in pagination and typographic detail.

Please cite the original version. 
1 Ionic liquids affect the adsorption of liposomes onto cationic polyelectrolyte coated silica evidenced

2 by quartz crystal microbalance

3

4 Filip Duša ${ }^{\mathrm{a}}$, Suvi-Katriina Ruokonen ${ }^{\mathrm{a}}$, Ján Petrovaj ${ }^{\mathrm{a}}$, Tapani Viitala ${ }^{\mathrm{b}^{*}}$, Susanne K. Wiedmer ${ }^{\mathrm{a}^{*}}$

5

6 a) Department of Chemistry, P. O. Box 55, 00014 University of Helsinki, Finland

7 b) Centre for Drug Research, Division of Pharmaceutical Biosciences, Faculty of Pharmacy, P. O. Box

856,00014 University of Helsinki, Finland

9

10

11 *) Correspondence: Dr. Susanne K. Wiedmer, Department of Chemistry, A.I. Virtasen aukio 1, P. O.

12 Box 55, 00014 University of Helsinki, Finland; phone: +358 294150183 or

13 Dr. Tapani Viitala, Centre for Drug Research, Division of Pharmaceutical Biosciences, Faculty of

14 Pharmacy, P. O. Box 56, 00014 University of Helsinki, Finland; phone: +358 294159626 


\section{Abstract}

17 The worldwide use of ionic liquids (ILs) is steadily increasing, and even though they are often referred 18 to as "green solvents" they have been reported to be toxic, especially towards aquatic organisms. In this 19 work, we thoroughly study two phosphonium ILs; octyltributylphosphonium chloride $\left(\left[\mathrm{P}_{8444}\right] \mathrm{Cl}\right)$ and 20 tributyl(tetradecyl)phosphonium chloride $\left(\left[\mathrm{P}_{14444}\right] \mathrm{Cl}\right)$. Firstly, the critical micelle concentrations $(\mathrm{CMCs})$

21 of the ILs were determined with fluorescence spectroscopy and the optical pendant drop method in order 22 to gain an understanding of the aggregation behavior of the ILs. Secondly, a biomimicking system of 23 negatively charged unilamellar liposomes was used in order to study the effect of the ILs on 24 biomembranes. Changes in the mechanical properties of adsorbed liposomes were determined by quartz 25 crystal microbalance (QCM) measurements with silica coated quartz crystal sensors featuring a 26 polycation layer. The results confirmed that both ILs were able to incorporate and alter the biomembrane 27 structure. The membrane disrupting effect was emphasized with an increasing concentration and alkyl 28 chain length of the ILs. In the extreme case, the phospholipid membrane integrity was completely 29 compromised.

\section{Keywords:}

32 Critical micelle concentration; Ionic liquids; Liposomes; Polybrene; Quartz crystal microbalance;

\section{Toxicity}




\section{Introduction}

Ionic liquids (ILs) are salts which typically are in melted state at temperatures below $100^{\circ} \mathrm{C}$. Their main benefits are a negligible vapor pressure, an ability to dissolve a large number of compounds, and the possibility to design on-demand ILs by combining different cations and anions [1]. Due to their low vapor pressures, ILs have often been referred to as "green solvents" because this enables an easier handling and storage of ILs [2]. Many recent studies, however, suggest that ILs possess a considerable toxicity, especially in aquatic environments $[1,3,4]$. ILs are frequently used in a large number of applications, yet there is still a considerable lack of information about their interaction with living organisms. Therefore, further characterization of ILs in this regard is of paramount importance.

Phosphonium-based ILs are a class of compounds where the phosphorus atom in the cation is typically bound to four alkyl substituents. In this work we investigate lipid membrane interactions with two commercially available phosphonium chloride ILs with long alkyl chains, namely octyltributylphosphonium chloride $\left(\left[\mathrm{P}_{8444}\right] \mathrm{Cl}\right)$ and tributyl(tetradecyl)phosphonium chloride $\left[\mathrm{P}_{14444}\right] \mathrm{Cl}$ (Figure 1). Recent applications include the use of phosphonium ILs for nucleation and electrodeposition of metals [5, 6], for analyte separations in analytical chemistry $[7,8]$, in liquid-liquid extractions $[9,10]$, and for selective capture and detection of arsenic [11]. Because cations of the ILs used in this study are amphiphilic we first evaluated whether these form micelles. The critical micelle concentration (CMC) is a very important characteristic of an amphiphilic compound. The CMC is reflected as a sudden change in solution properties when micelles are formed [12]. The formation of micelles may affect the way the compounds interact with biomembranes. There are several methods for CMC determination, such as conductivity, NMR diffusion, surface tension, fluorescence spectroscopy, and others (see reference [13]). CMC values in this study were determined with fluorescence spectroscopy and surface tension analysis. 
The biomembrane is one of the key cellular structures, which protects a cell from the external

60 environment. Thus, any alteration or disruption of the biomembrane can have serious or even lethal consequences for the organism. It has recently been reported that imidazolium based ILs can induce membrane fusion [14] and alter membrane permeability [15]. Much in the same way as certain amphipathic $\alpha$-helical peptides, positively charged surfactants, and other peptides [16-21]. Therefore, further knowledge about the behavior of phosphonium ILs in regard to their interactions with biomembranes can bring light onto possible benignity or toxicity of particular ILs.

Coating of surfaces with phospholipids is often a method of choice for studying interactions between model biomembranes and various compounds [22, 23]. Furthermore, it is possible to obtain a deeper understanding about the mechanism of how compounds influence the membrane structure by observing changes in the properties of phospholipid layers adsorbed on solid surfaces [19, 24]. Advanced quartz crystal microbalance techniques (QCM), i.e. impedance based QCM or QCM with dissipation monitoring, are powerful tools for determining various properties (e.g. thickness, mass, and viscoelasticity) and interaction dynamics of adsorbed layers. One of the main advantages of advanced QCM techniques is that they enable fast and label-free detection of compounds interacting with the sensor [25]. The resonance frequency of a quartz crystal sensor is dependent on the mass of the adsorbed layer, whereas the change in energy dissipation of the sensor $(\Delta \mathrm{D})$ provides information about viscoelastic properties of the adsorbed layer. In this regard, advanced QCM can be considered as a biosensing device where the resonance frequency and energy dissipation of the sensor with a bound biological structure (e. g. lipid bilayer/liposomes) will change upon addition of ILs interacting with the system [25, 26]. Advanced QCM can also provide highly relevant information about disruption of lipid bilayers [27], 81 interaction with membrane active moieties [28], binding dynamics [26], and lipid packing density [29]. 
82 Zwitterionic and anionic phospholipids are the most abundant components of biomembranes. In this

83 work, zwitterionic egg L- $\alpha$-phosphatidylcholine (eggPC) and negatively charged 1-palmitoyl-2-oleyl-sn-

84 glycero-3-[phospho-rac-(1-glycerol)] (POPG) were used for preparation of liposomes. These liposomes

85 were used in the form of large unilamellar vesicles with approximate diameters of $130 \mathrm{~nm}$. Such a system

86 was used in our previous study, where interactions between liposomes and ILs were investigated with

87 capillary electromigration techniques [30]. In order to better understand the interactions observed in our

88 previous study, this work focused on the characterization of ILs and their influence on liposomes. It has

89 already been shown that liposomes bind to silica surface, and based on their composition, size,

90 concentration, and experimental conditions they can either adsorb as intact liposomes or rupture to form

91 phospholipid bilayers on the silica surface [21, 31, 32]. Increase in porosity of such silica surfaces has

92 also been reported to increase the kinetics of vesicle rupture and bilayer formation [33]. The liposomes

93 used in our study were highly negatively charged due to $25 \mathrm{~mol} \%$ of anionic POPG. Since the silica

94 surface of the QCM sensor was negatively charged at the used $\mathrm{pH}$ of 7.4 (the $\mathrm{p} K_{\mathrm{a}}$ value of the silanol

95 groups is approximately 4.9, meaning almost complete dissociation), it was necessary to apply a fast and

96 reliable coating method with cationic layer. This prevented unwanted interactions with the cationic ILs,

97 which would eventually result in the formation of a 'dynamic' IL coating. Furthermore, it ensured fast

98 liposome binding to the sensor surface. Positively charged polyelectrolyte coatings can be utilized to

99 screen off the surface interactions between positively charged compounds and the negatively charged

100 silanols [34]. Polybrene, a widely used cationic polyelectrolyte for coating of silica [35], was employed

101 in this work. The same polyelectrolyte was also utilized in our recent capillary electrophoresis study of

102 interactions between the same liposome-ILs systems with common pharmaceutics [30]. In this work, we

103 will demonstrate that QCM is a highly suitable technique for analysis of interactions between

104 phosphonium ILs and phospholipid membranes, providing new insight into the possible mechanism of 
105 ILs toxicity. Moreover, the QCM methodology will also be used to bring complimentary information on

106 trends and phenomenon observed in our previous study [30].

107

108 2. Materials and methods

109 2.1 Chemicals

110 POPG (sodium salt) was purchased from Genzyme Pharmaceuticals (Liestal, Switzerland), EggPC (Egg,

111 Chicken) was purchased from Avanti Polar Lipids (Alabaster, AL, USA). Polybrene (hexadimethrine

112 bromide) was purchased from Fluka (Buchs, Switzerland). Hydrogen sodium phosphate, hydrogen

113 peroxide $\left(\mathrm{H}_{2} \mathrm{O}_{2} ; 50 \%\right.$ weight in $\left.\mathrm{H}_{2} \mathrm{O}\right)$, ammonium hydroxide $\left(\mathrm{NH}_{4} \mathrm{OH} ; 30 \%\right.$ weight in $\left.\mathrm{H}_{2} \mathrm{O}\right)$, and 3-[(3-

114 cholamidopropyl)dimethylammonio]-1-propanesulphonate (CHAPS) (purity of 98\%) were purchased

115 from Sigma (Darmstadt, Germany). Dihydrogen sodium phosphate monohydrate and HPLC-grade

116 methanol were from Mallinckrodt Baker (Deventer, The Netherlands). The pH calibration solutions (7.01

117 and 10.01) were purchased from Merck (Darmstadt, Germany). Sodium hydroxide (1.0 M) was from FF-

118 Chemicals (Yli-Ii, Finland) and chloroform from Rathburn (Walkerburn, UK). Distilled water was

119 further purified with a Millipore water-purification system (Millipore, Molsheim, France). Sodium

120 dodecyl sulfate (SDS, purity of 99\%) and pyrene (GC-grade; purity of 99\%) were obtained from Merck

121 (Darmstadt, Germany) and Fluka (Sigma-Aldrich, Switzerland), respectively. 1-Ethyl-3-

122 methylimidazolium acetate [emim][OAc] was purchased from Iolitec GmbH (Heilbronn, Germany).

$123\left[\mathrm{P}_{8444}\right] \mathrm{Cl}$ and $\left[\mathrm{P}_{14444}\right] \mathrm{Cl}$ were provided by Cytec Industries (Woodland Park, NJ, USA).

124 
126 Sodium phosphate buffer was prepared by mixing disodium hydrogen phosphate and sodium dihydrogen

127 phosphate to yield an ionic strength of $10 \mathrm{mM}$ and a $\mathrm{pH}$ of 7.4. The buffer solution was filtered through 128 a $0.45-\mu \mathrm{m}$ polytetrafluoroethylene syringe filter (Gelman Sciences, Ann Arbor, MI, USA) before use.

129 Sodium phosphate buffer was used as a solvent for liposomes and ILs preparation and as a solvent in all 130 QCM and CMC measurements.

\subsection{Liposome preparation}

133 A $3.0 \mathrm{mM}$ dispersion of liposomes was prepared by mixing appropriate volumes of stock solutions of 134 eggPC $(20 \mathrm{mM})$ and POPG $(15 \mathrm{mM})$ in chloroform. The mixing ratio of lipid stock solutions in 135 chloroform was 75/25 molar percentage of eggPC/POPG. The resulting mixture was dried under a stream 136 of pressurized air and chloroform residues were removed by overnight evacuation in an exicator. The 137 phospholipids were hydrated in the sodium phosphate buffer for $60 \mathrm{~min}$ at $60^{\circ} \mathrm{C}$ and shaken continuously 138 to yield multilamellar vesicles. The resulting dispersion was processed to large unilamellar vesicles by 13919 times extrusion through 100-nm pore sized polycarbonate filters (Millipore, Bedford, MA, USA) with 140 a Liposo-Fast extruder (AVESTIN, Ottawa, ON, Canada). Liposome sizes of approximately $130 \mathrm{~nm}$ were routinely confirmed by Malvern Zeta Sizer (Malvern, Great Britain).

\subsection{Fluorescence spectroscopy}

144 The fluorescence spectroscopy measurements were performed at room temperature with a FluoroMax4

145 Spectrofluorometer (Horiba Jobin Yvon, Edison, NJ, USA). Fluorescence emission spectra of IL or SDS 146 solutions, containing $0.1 \mu \mathrm{M}$ of pyrene, were measured at $391 \mathrm{~nm}$ using a $1 \mathrm{~cm}$ quartz cuvette. The SDS

147 measurements were performed to confirm that the system was working appropriately. The aggregation 148 of surfactants, using pyrene as a fluorescence probe, was evaluated from the emission spectra by 
149 determining the intensity ratios of the first and third vibronic peak $\left(\mathrm{I}_{1} / \mathrm{I}_{3}\right)$ located near 370 and $380 \mathrm{~nm}$, 150 respectively. Excitation and emission slits were set at $5 \mathrm{~nm}$ and $1 \mathrm{~nm}$, respectively. The collection and 151 evaluation of data was performed with the FluorEssence software (Horiba Scientific, Edison, NJ, USA).

152 All fluorescence measurements were repeated three times. The relative standard deviation of sequential 153 measurements of the pyrene $1: 3$ ratio did not exceed $1 \%$.

155 A $1 \mu \mathrm{M}$ pyrene stock solution was prepared by dissolving pyrene in water, followed by bath sonication 156 for $30 \mathrm{~min}$. The pyrene water solution was oscillated at room temperature in the dark overnight in order 157 to get a saturated stock solution. $50 \mathrm{mM}$ SDS stock solution and $10 \mathrm{mM}$ IL stock solutions were prepared 158 by dissolving an appropriate amount of surfactant in water or sodium phosphate buffer. Diluted solutions 159 were shaken for $15 \mathrm{~min}$ and sonicated for another $15 \mathrm{~min}$. Solutions were protected from light and stored

160 at $4{ }^{\circ} \mathrm{C}$. Dilution series for fluorescence measurements were prepared by mixing appropriate amounts of 161 surfactants in a saturated pyrene solution to get concentrations between $0.1-3.0 \mathrm{mM}$. Prior to any analysis 162 the prepared solutions were shaken and sonicated for 15 min in the dark. All CMC analyses were done 163 at $25^{\circ} \mathrm{C}$.

165 The $\mathrm{CMC}$ value $\left(x_{\mathrm{CMC}}\right)$ was derived according to the method by Aguiar et al. [36]. The Boltzmann 166 sigmoid function (equation 1) was fitted to a pyrene 1:3 ratio versus surfactant concentration plot with 167 ORIGIN 8.0 (OriginLab, MA, USA) to extract the parameters $x_{0}$ (i.e. the sigmoid center) and $\Delta x$ (i.e. 168 range in which the pyrene 1:3 ratio drop occurs). The CMC values were then determined by using 169 equation 2 and the extracted $x_{0}$ and $\Delta x$ parameters.

170

$171 \quad y=\frac{A_{2}-A_{1}}{1+e^{\frac{x-x_{0}}{\Delta x}}}+A_{2}$ 
173 In Equation 1 the parameters A1 and A2 are the higher and lower limits of the sigmoid, respectively. 174

$175 \quad x_{C M C}=x_{0}-2 \cdot \Delta x$

176

177

\subsection{Optical pendant drop method}

178 The surface tension measurements were performed with the pendant drop method at room temperature with a CAM 200 Optical Contact Angle Meter (Biolin Scientific, Attension, Finland) equipped with a

180 CCD Video Camera Module. Measurements were performed by collecting 20 frames at a frame interval 181 of 1 s. Evaluation of the data was performed with the Attension Theta Software (ver. 4.1.0, Biolin 182 Scientific, Finland). Fitting of collected images was done with the Young-Laplace equation. ILs were 183 diluted in MilliQ water and sodium phosphate buffer and each sample was measured three times.

\subsection{Quartz crystal microbalance}

186 Interactions between additives and silica were performed with an impedance-based quartz crystal 187 microbalance technique (QCM-Z500; KSV, Biolin Scientific, Finland). Individual experiments were performed by using a constant liquid flow of $300 \mu \mathrm{L} \mathrm{min}^{-1}$ through the QCM flow channel thermostated at $20{ }^{\circ} \mathrm{C}$. Before use, the silica coated quartz crystal sensors were conditioned by using the following

190 procedure. The quartz crystal sensor was first immersed for 5 min into a boiling solution of $\mathrm{NH}_{4} \mathrm{OH} / \mathrm{H}_{2} \mathrm{O}_{2} / \mathrm{H}_{2} \mathrm{O}(1 / 1 / 5 \mathrm{v} / \mathrm{v} / \mathrm{v})$. Hereafter, the quartz crystal sensor was washed with water and dried

192 with air. After placing the quartz crystal sensor into the measuring chamber, a coating method consisting of five subsequent $400 \mathrm{~s}$ washes of water, $0.1 \mathrm{M}$ sodium hydroxide, water, $1 \%$ polybrene (in water) $(\mathrm{m} / \mathrm{v})$, and water was applied. For polybrene-free measurements the chip was only washed with water, $0.1 \mathrm{M}$ 
196

197

198

199

200

201

202

203

204

205

206

207

208

209

210

211

212

213

214

215

216

217

each analysis, followed by a $200 \mathrm{~s}$ wash with a $0.3 \mathrm{mM}$ liposome dispersion. Subsequently $400 \mathrm{~s}$ washes with solutions of increasing IL concentrations were applied. After each complete measurement the silica coated quartz crystal sensor was cleaned in situ in the QCM flow channel by washing it with $20 \mathrm{mM}$ CHAPS, 0.1 M sodium hydroxide, ethanol, and water. The QCM flow channel was filled with water between the analyses.

Resonance parameters were measured at the fundamental frequency of around $5 \mathrm{MHz}$ and at four overtones ( $\mathrm{n}=3,5,7$, and 9 , corresponding to frequencies close to $15,25,35$, and $45 \mathrm{MHz}$ ). The data obtained from the QCM measurements were analyzed with the QCM-Z500 data analysis software suite, version 3.30, and the adsorbed layer thickness along with the viscoelastic properties were determined by using a Voigt viscoelastic representation of the adlayer as described by Bandley et al. [37]. The following starting parameters were used for fitting the viscoelastic film properties: film thickness of $0.01 \mu \mathrm{m}$, film elasticity of $0.1 \mathrm{MPa}$, and film viscosity of $0.001 \mathrm{~Pa} \cdot \mathrm{s}^{-1}$. The density of the surrounding liquid and the density of the formed liposome layer or lipid bilayer were kept constant at $0.9986 \mathrm{~g} \cdot \mathrm{cm}^{-1}$ and $1.06 \mathrm{~g} \cdot \mathrm{cm}^{-1}$ $[38,39]$. Relaxation times were finally obtained by dividing the calculated layer viscosity by the calculated layer elasticity.

\section{Results and discussion}

The aim of the work was to gain further insight into how ILs interact with liposomes. First, the CMCs values of the studied ILs were determined in order to evaluate their surfactant properties. Second, QCM was applied to obtain information on the change of mechanical properties of liposomes when exposed to surface active compounds. Moreover, a silica coating adsorption study of a positively charged polyelectrolyte layer was also done with QCM. This system was recently utilized in one of our capillary electrophoresis studies [30]. The results obtained from polyelectrolyte layer - liposome - ILs interaction 
studies would therefore also help to gain a better understanding on the behavior of polyelectrolyte modified fused silica systems used in capillary electrophoresis.

\subsection{Determination of CMC of ILs}

224 In our recent study, we have observed that the ILs used in this work suppress the electroosmotic flow (EOF) in fused silica capillaries [30]. In this work, the CMCs were determined in order to investigate if the suppression of the EOF by these ILs was related to their self-aggregation. The aggregation of ILs might also influence their interactions with liposomes; hence, CMC values of the phosphonium ILs in water and in phosphate buffer were determined using fluorescence spectroscopy and surface tension analysis.

In the fluorescence spectroscopy approach, the CMC values were determined by using a pyrene 1:3 ratio method [40], where solvent dependent fluorescence emissions of pyrene were determined. The characteristic emission spectra of pyrene, shown in Figure 3B, have five maxima in the range 360-400 nm (Figure 3B). The first $\left(I_{1}\right)$ and third $\left(I_{3}\right)$ vibronic bands of the pyrene emission spectrum are located at 370 and $380 \mathrm{~nm}$, respectively, and their intensities are highly dependent on the polarity of the environment of the pyrene probe. Below the CMC the 1:3 pyrene ratio is dependent on the polarity of the solution, while above the $\mathrm{CMC}$ it decreases rapidly because the probe transfers to the more hydrophobic environment inside the aggregated surfactants [40].

As a comparison, $\mathrm{CMC}$ values were also determined with the optical pendant drop method. When the concentration of a surface-active compound increases, the monomers orientate at the surface of the drop 242 in order to decrease the free energy of the system until the surface is fully covered. The surface tension of the drop, therefore, decreases until the $\mathrm{CMC}$ is reached. Hereafter, the surface tension levels out and 
244 reaches an almost constant value due to the aggregation of any further monomers introduced to the system 245 [41]. The surface tension values were derived by fitting the Young-Laplace equation to drop shapes of 246 solutions with increasing IL concentration. The CMC value was then derived from the intersection point 247 of two trend lines when the surface tension was plotted against an increasing concentration of the 248 corresponding IL.

250 The plot of surface tension versus concentration of $\left[\mathrm{P}_{8444}\right] \mathrm{Cl}$ is shown in Figure 2. The CMC values of $251\left[\mathrm{P}_{8444}\right] \mathrm{Cl}$ in either water or phosphate buffer could not be determined due to the lack of a clear breakpoint 252 in the surface tension-concentration curve. The surface tension of the $\left[\mathrm{P}_{8444}\right] \mathrm{Cl}$ solutions decreased 253 without reaching a constant value, indicating that additional monomers were assembling at the surface 254 of the drop rather than forming full-size micelles. The decrease was, however, not linear, which indicates 255 that $\left[\mathrm{P}_{8444}\right] \mathrm{Cl}$ monomers aggregate to form oligomers but no micelles in a similar way as has previously 256 been shown for other surfactant systems [42, 43]. In addition, the steepest change in the surface tension 257 occurred in the concentration range from 5 to $10 \mathrm{mM}$, which can be taken as an indication of the onset 258 of aggregation. In contrast to phosphonium ILs, aggregation of imidazolium based ILs has been 259 investigated by several research groups [44]. Blesic et al. have suggested that imidazolium cations 260 possessing at least eight carbons, with chlorine anions, can form micelles [45]. Chen et al. have shown 261 that close-to-spherical charged micelles can already be formed when the alkyl chain contains more than 262 four carbons [46]. These findings are in contradiction with the behavior observed for $\left[\mathrm{P}_{8444}\right] \mathrm{Cl} . \mathrm{We}$ 263 speculate that the bulky headgroup of $\left[\mathrm{P}_{8444}\right] \mathrm{Cl}$ which contains three butyl chains makes a sterical 264 obstacle for a neat arrangement and further aggregation of the molecules, thus preventing micelle 265 formation in this case. 
267 The $\mathrm{CMC}$ values of $\left[\mathrm{P}_{14444}\right] \mathrm{Cl}$ determined by fluorescence spectroscopy were $0.90 \mathrm{mM}$ in water and 0.60 $268 \mathrm{mM}$ in the phosphate buffer, respectively. The corresponding values measured using the optical pendant 269 drop method were $0.92 \mathrm{mM}$ and $0.54 \mathrm{mM}$, respectively (Figure 3). The lower CMC value of $\left[\mathrm{P}_{14444}\right] \mathrm{Cl}$ 270 in phosphate buffer compared to water originates from the fact that an increased concentration of ions in 271 the buffer system stabilizes the aggregates by reducing the repulsion between polar head groups leading 272 to a decrease in the CMC value [47, 48]. The results of both techniques correlate very well with each 273 other, which indicates that both techniques are suitable for CMC determinations of the ILs used in this 274 work.

\subsection{Quartz crystal microbalance}

QCM experiments were performed to find out how liposomes used as model cell biomembranes interact with ILs. The QCM method appears to be an excellent choice for such measurements as it can measure not only a change in adsorbed mass but it can also provide an estimate of the thickness and mechanical properties of an adsorbed layer. Motivation to this work was based on findings from our recent liposome electrokinetic chromatography study [30]. There, we observed that eggPC/POPG liposomes did not at all adsorb on bare silica capillaries, whereas they were readily adsorbed on polybrene coated fused silica capillary walls, consequently resulting in a doubly reversed electroosmotic flow. Hence, a silica coated sensor with and without adsorbed polybrene was used in this study to obtain a deeper understanding of the system previously used for electrokinetic chromatography studies.

As noticed in our previous study on fused silica capillaries [30], neither in this work did we observe any adsorption of negatively charged eggPC/POPG liposomes onto the bare silica coated sensor (Figure S1).

This is in contrast with available literature where negatively charged liposomes have been shown to adhere to the silica surface of a QCM sensor $[49,50]$. Furthermore, the adsorption behavior of different 
compositions of liposomes in connection to the formation of supported lipid bilayers (SLB) on silica and 292 other polar surfaces such as glass, quartz, titania, mica, etc. has been thoroughly investigated by QCM 293 and related techniques $[21,32,50,51]$. For example, positively charged liposomes (i.e. DOTAP) were 294 shown to readily adhere to a negatively charged silica surface and instantly form an SLB, while a highly 295

312 The polybrene coating process of the silica surface was optimized in our previous capillary 313 electrophoresis study [30]. In this work, the same coating procedure was utilized before each QCM 314 experiment. A $0.1 \mathrm{M} \mathrm{NaOH}$ wash was used to deprotonate the silanol groups and to enhance the 
315 adsorption of polybrene. During the optimization, it was found that a $1 \%(\mathrm{~m} / \mathrm{v})$ concentration of 316 polybrene in water coated the silica sensor with a polybrene layer of a thickness of $\sim 1 \mathrm{~nm}$. This correlates 317 well with the thickness of a polybrene layer on silica recently determined by atomic force microscopy 318 [56]. After the silica sensor was coated with polybrene, the EggPC/POPG liposomes adhered almost 319 instantly on the sensor surface forming a lipid layer with an average modeled thickness of $\sim 19 \mathrm{~nm}(\mathrm{n}=$ 320 6). The averaged modeled thickness of the EggPC/POPG lipid layer in this study closely resembles the 321 modeled thickness of liposome layers reported in the literature, i.e. $22 \mathrm{~nm}$ for a POPC liposome layer on 322 removed during the surfactant/sodium hydroxide/ethanol cleaning step. a gold coated quartz crystal sensor [57] and $17 \mathrm{~nm}$ for an EggPC/POPS liposome layer on a gold coated quartz crystal sensor functionalized with $\mathrm{H}_{2} \mathrm{C}=\mathrm{CH}-\left(\mathrm{CH}_{2}\right)_{9}-\mathrm{PEG}-\left(\mathrm{CH}_{2}\right)_{10}-\mathrm{SH}$ [58]. These studies in combination with the fact that the adsorption of EggPC/POPG liposomes on the polybrene coated sensor surface is accompanied with a large dissipation change, strongly suggest that the EggPC/POPG liposomes adsorb on the polybrene coated sensor surface as intact liposomes. Other studies in the literature, however, have reported a larger modeled layer thickness in the range of $33-42 \mathrm{~nm}$ for adsorbed liposome layers on oxidized gold, $\mathrm{TiO}_{2}$, and $\mathrm{Al}_{2} \mathrm{O}_{3}$ surfaces $[59,60]$. This, on the other hand, suggests that the EggPC/POPG liposome layer adsorbed on the polybrene coated sensor surface is composed of highly truncated liposomes caused by the strong electrostatic interaction between the negatively charged liposomes and the positively charged polybrene surface. Liposome adsorption was also tested if the polybrene coating step was skipped before an analysis. The results showed that the liposomes still adhered to the sensor surface, unless the sensor was treated with a boiling solution of the oxidative cleaning mixture (i.e. $\mathrm{NH}_{4} \mathrm{OH} / \mathrm{H}_{2} \mathrm{O}_{2} / \mathrm{H}_{2} \mathrm{O}$ ). This suggests that polybrene was not totally

There was almost no observable effect on the adsorbed EggPC/POPG liposomes when both phosphonium ILs at a concentration of $2.8 \mu \mathrm{M}\left(10^{-4} \% \mathrm{~m} / \mathrm{v}\right)$ were allowed to interact with the liposome layer (Figure 
4). A frequency decrease was, however, observed when the liposome layer was exposed to higher 340 concentrations of the ILs. In the case of $\left[\mathrm{P}_{8444}\right] \mathrm{Cl}$, a concentration of $0.28 \mathrm{mM}\left(10^{-3} \% \mathrm{~m} / \mathrm{v}\right)$ and higher 341 induced a fast decrease in the frequency within 2 minutes, whereafter the frequency stabilized at a 342 constant level. At the same time a slight initial decrease in the dissipation was observed using a $\left[\mathrm{P}_{8444}\right] \mathrm{Cl}$ 343 concentration of $0.28 \mathrm{mM}$, whereas a large increase in dissipation was observed at higher concentrations of $\left[\mathrm{P}_{8444}\right] \mathrm{Cl}$ (Figure $\mathrm{S} 2$ ). This behavior was also reflected in a continuous increase in the modeled thickness of the liposome layer at $\left[\mathrm{P}_{8444}\right] \mathrm{Cl}$ concentrations higher than $0.28 \mathrm{mM}$. However, decrease in frequency, increase in dissipation, and increase in the modeled layer thickness all reversed their trend when exposing the liposome layer to a $\left[\mathrm{P}_{8444}\right] \mathrm{Cl}$ concentration of $28 \mathrm{mM}(1 \% \mathrm{~m} / \mathrm{v})$ for over 3 minutes.

348 The increase in frequency and decrease in dissipation continued even after the $28 \mathrm{mM}\left[\mathrm{P}_{8444}\right] \mathrm{Cl}$ solution was changed to buffer. At the end of the measurements, the dissipation had dropped to a three times smaller value than the maximum dissipation value, and the modeled layer thickness was in the range of 3.1 to $13.5 \mathrm{~nm}$ (Figure 4 and S2). This indicates that the remaining lipid layer is a mixture of lipid bilayers and unruptured liposomes. These findings show that $\left[\mathrm{P}_{8444}\right] \mathrm{Cl}$ interacts with the liposomes either by adsorbing on the liposome surfaces or incorporating into the bilayer at low concentrations, while at higher concentrations its abundance in the liposome bilayer reaches a level that destabilizes the lipid bilayer 355 structure of the liposomes, consequently inducing liposomes to rupture and fuse. Similar frequency/dissipation have recently been observed with DPPC supported lipid vesicles interacting with melittin [61]. The effect is called "carpet" mechanism where interacting compound first adsorbs onto the phospholipid layer and after a certain amount of time, when a threshold value is reached, insertion into the lipid bilayer begins. This is followed by membrane perforation, peptide-lipid complexes and water are released, and eventually an SLB is formed [61, 62]. The same scenario is also supported by the relaxation time which illustrates the visco-elasticity of an adsorbed layer. The higher the relaxation time 
was exposed to liposomes, the relaxation time increased until the concentration reached $28 \mathrm{mM}(1 \%)$. Hereafter, the relaxation time dropped due to the rupturing of the liposome layer (see Figure 5).

When the EggPC/POPG liposome layer was allowed to interact with $\left[\mathrm{P}_{14444}\right] \mathrm{Cl}$ concentrations of $10^{-3} \%$ $(\mathrm{m} / \mathrm{v})$ and $10^{-2} \%(\mathrm{~m} / \mathrm{v})$ the frequency decreased quickly and leveled out at a constant value within $\sim 2$ minutes, while the dissipation simultaneously increased (Figure 4 and S3). This is also reflected in the modeled layer thickness, as well as in a constant increase in the relaxation time (Figure 6). These results show that the interaction of $\left[\mathrm{P}_{14444}\right] \mathrm{Cl}$ with the adsorbed liposome layer causes both a mass increase and

a change in the mechanical properties of the liposome layer; hence, the interaction of $\left[\mathrm{P}_{14444}\right] \mathrm{Cl}$ destabilizes the lipid bilayer of the liposomes by incorporation into the bilayer, thus compromising the neat lipid bilayer structure. Hexadecyltrimethylammonium bromide (CTAB) which is similar in structure to $\left[\mathrm{P}_{14444}\right] \mathrm{Cl}$ has recently been shown to decrease the degree of organization of an DPPC liposome bilayer [63]. When the concentration of $\left[\mathrm{P}_{14444}\right] \mathrm{Cl}$ increased above its $\mathrm{CMC}(\sim 0.6 \mathrm{mM}$; see section 3.1) to 2.30 $\mathrm{mM}(0.1 \% \mathrm{~m} / \mathrm{v})$ the frequency increased and the dissipation decreased quickly back to the zero level. This is a clear indication that the liposome layer was completely compromised and removed from the sensor surface by dissolution of the phospholipids into $\left[\mathrm{P}_{14444}\right] \mathrm{Cl}$ micelles. Mechanics of observed disintegration could be similar to a three-step process of interaction of POPC giant unilamellar liposomes with cetylpyridinium chloride (CPC): first the CPC was incorporated into the bilayer structure; then an ellipsoidal change in the liposome shape was observed just before a membrane saturation with CPC; and finally the POPC bilayer was solubilized after the saturation threshold was reached [64].

In addition, QCM experiments on mixed systems of liposomes and ILs with the polybrene coated sensor were carried out. The underlying motivation was to mimic the conditions in the CE capillary measurements where premixed systems like this have been used [30]. The polycation coated sensor was 
washed with solutions of $0.3 \mathrm{mM}$ liposomes pre-mixed with 0.23 or $0.28 \mathrm{mM}(0.01 \% \mathrm{~m} / \mathrm{v})$ solutions of $388\left[\mathrm{P}_{8444}\right] \mathrm{Cl}$ or $\left[\mathrm{P}_{14444}\right] \mathrm{Cl}$, respectively. The adsorption of the EggPC/POPG/[P $\left.{ }_{8444}\right] \mathrm{Cl}$ mixture on the polybrene surface was very rapid $(\approx 3 \mathrm{~min})$, whereas it took almost 10 minutes for the EggPC/POPG/[P $\left.{ }_{14444}\right] \mathrm{Cl}$ mixture to reach an equilibrium frequency level (Figure 7). This suggests that neither of the ILs tested were able to fully screen the surface charges of the negatively charged liposomes.

392 Furthermore, the adsorption of the EggPC/POPG/[P $\left.{ }_{8444}\right] \mathrm{Cl}$ mixture caused significantly larger frequency and dissipation changes, and consequently also formed a layer with a larger modeled thickness compared to the EggPC/POPG/[P $\left.{ }_{14444}\right] \mathrm{Cl}$ mixture (Figures $7, \mathrm{~S} 4$, and S5 ). This agrees very well with the results above where it was shown that the $\left[\mathrm{P}_{14444}\right] \mathrm{Cl}$ has a stronger tendency to destabilize and compromise the neat structure of the phospholipid bilayer in the liposomes compared to $\left[\mathrm{P}_{8444}\right] \mathrm{Cl}$.

Based on the results above it is apparent that both ILs in this study were able to significantly alter the membrane structure and viscoelastic properties of negatively charged liposomes. The industry is continually opting for utilizing similar phosphonium liquids as used in this study as solvents for a broad range of applications, which means that there is an overly increasing risk of their unintentional environmental release. Quaternary ammonium cations, which are very close in structure to the investigated ILs, are commonly utilized as disinfectants (e.g. Cetrimide containing a mixture of C12-, C14-, and C16-trimethylammonium bromide). Concentrations in the range of $0.1-1$ mass $\%$ are often 405 used in medicine either for disinfection of skin and wounds or contaminated instruments [65]. The influence of $\mathrm{CTAB}$ in the concentration range from 10 to 50 molar percent on the morphology of phosphatidylcholine SLBs was recently thoroughly investigated [63]. The results from that study showed that CTAB had a clear effect on decreasing the degree of organization of the lipid bilayer. The CMC of CTAB is $0.92 \mathrm{mM}$ [66], which is very close to the $\mathrm{CMC}$ of $\left[\mathrm{P}_{14444}\right] \mathrm{Cl}$. An effective concentration for 
411 might have detrimental effects on cell membranes due to the ability of $\left[\mathrm{P}_{14444}\right] \mathrm{Cl}$ to destabilize and 412 completely compromise or dissolve phospholipid bilayers at these concentrations. Moreover, the 413 biodegradability of phosphonium ILs is substantially lower compared to ammonium, imidazolium, and 414 pyrimidinium ILs [67]. It appears that $\left[\mathrm{P}_{8444}\right] \mathrm{Cl}$ possesses a slightly less disruptive activity on the 415 investigated liposomes compared to $\left[\mathrm{P}_{14444}\right] \mathrm{Cl}$ mainly due to temporal incorporation effects. Our findings 416 show that ILs could potentially be harmful in aquatic environments even if pure ILs are diluted thousand 417 fold (or hundred fold for $\left[\mathrm{P}_{8444}\right] \mathrm{Cl}$ ). Furthermore, the long-time effects of concentrations below CMC 418 should be further investigated for $\left[\mathrm{P}_{14444}\right] \mathrm{Cl}$ due to its ability to strongly associate with the phospholipid 419 membrane at concentrations as low as $10^{-3} \%(\mathrm{~m} / \mathrm{v})$.

420 


\section{Conclusions}

422 We have performed interaction studies of two phosphonium ILs and negatively charged EggPC/POPG 423 liposomes. The CMCs of the ILs were obtained by fluorescence spectroscopy and the optical pendant 424 drop method. Both methods were in good agreement, indicating a good reproducibility and accuracy of 425 the CMC values. Furthermore, QCM was used as a fast and reliable method to obtain a deeper insight 426 into the interactions of the ILs and liposomes adsorbed on a polybrene coated silica surface. The QCM 427 measurements showed that the long alkyl chain IL, $\left[\mathrm{P}_{14444}\right] \mathrm{Cl}$, was associating more strongly with the 428 liposomes compared to the shorter IL, $\left[\mathrm{P}_{8444}\right] \mathrm{Cl}$. At moderate concentration both ILs caused a change in 429 the viscoelasticity of the phospholipid membrane which is attributed to destabilization of the 430 phospholipid membrane, thus causing the liposomes to swell. At higher concentration, $\left[\mathrm{P}_{8444}\right] \mathrm{Cl}$ induced 431 vesicle rupture, whereas $\left[\mathrm{P}_{14444}\right] \mathrm{Cl}$ completely compromised or dissolved the liposomes at a 432 concentration higher than its CMC. Additional experiments showed that liposomes in pre-mixed systems 433 with sub-millimolar concentrations of ILs adhered readily to the polybrene coated silica sensor, showing 434 that the positively charged ILs were not able to fully screen the negatively charged liposomes. We have 435 provided evidence that new "green solvents," such as ILs, might disturb the structural stability of 436 phospholipid membranes even at very low concentrations and, therefore, we encourage further studies 437 of such compounds in connection to their toxicity, especially towards aquatic organisms. 


\section{Acknowledgment}

439 Financial support from the Academy of Finland, project numbers 266342 (SKW), 276075 (SKW), 440263861 (TV), and 137053 (TV), and from Magnus Ehrnrooth Foundation (SKW) is greatly 441 acknowledged. Jeff Dyck and Al Robertson from Cytec Industries are gratefully acknowledged for 442 providing their off-the-shelf phosphonium chloride salts.

\section{Authors' contributions}

445 Filip Duša participated in drafting and revising the manuscript, and in conducted the QCM 446 measurements. Suvi-Katriina Ruokonen participated in drafting and revising the manuscript. Ján Petrovaj 447 conducted fluorescence and surface tension measurements. Tapani Viitala participated in the QCM 448 analysis and critically revised the manuscript. Susanne K. Wiedmer designed the project and critically 449 revised the manuscript. All authors gave final approval for publishing the manuscript. 


\section{References}

452 [1] T.P. Pham, C.W. Cho, Y.S. Yun, Water Res, 44 (2010) 352-372.

453 [2] M.J. Earle, K.R. Seddon, Pure Appl. Chem., 72 (2000) 1391-1398.

454 [3] V. Tsarpali, S. Dailianis, Ecotoxicol. Environ. Saf., 117 (2015).

455

[4] H. Chen, Y.Q. Zou, L.J. Zhang, Y.Z. Wen, W.P. Liu, Aquat. Toxicol., 154 (2014) 114-120.

456

[5] X.Y. Chen, G.S. Goff, M. Quiroz-Guzman, D.P. Fagnant, Jr., J.F. Brennecke, B.L. Scott, W.

457 Runde, Chem. Commun. (Cambridge, U. K.), 49 (2013) 1903-1905.

458 [6] A. Izgorodin, O. Winther-Jensen, B. Winther-Jensen, D.R. MacFarlane, Phys. Chem. Chem. Phys., 45911 (2009) 8532-8537.

460 [7] J.V. Seeley, S.K. Seeley, E.K. Libby, Z.S. Breitbach, D.W. Armstrong, Anal Bioanal Chem, 390 461 (2008) 323-332.

462 [8] J. Lokajová, A. Railila, A.W.T. King, S.K. Wiedmer, J. Chromatogr. A, 1308 (2013) 144-151.

463 [9] M.Y. Yang, P.J. Zhang, L. Hu, R.H. Lu, W.F. Zhou, S.B. Zhang, H.X. Gao, J. Chromatogr. A, 1360 464 (2014) 47-56.

465 [10] J.M. Padro, R.B.P. Vidal, M. Reta, Anal. Bioanal. Chem., 406 (2014) 8021-8031.

466 [11] Z.Q. Tan, J.F. Liu, Y.G. Yin, Q.T. Shi, C.Y. Jing, G.B. Jiang, ACS Appl. Mater. Interfaces, 6 467 (2014) 19833-19839.

468 [12] G.S. Hartley, Aqueous solutions of paraffin-chain salts; a study in micelle formation, Hermann, 469 Paris, 1936.

470 [13] B. Natalini, R. Sardella, A. Gioiello, F. Ianni, A. Di Michele, M. Marinozzi, J. Pharm. Biomed. 471 Anal., 87 (2014) 62-81.

472 [14] P. Galletti, D. Malferrari, C. Samorì, G. Sartor, E. Tagliavini, Colloids Surf., B, 125 (2015) 142473150.

474 [15] H. Lee, T.J. Jeon, Phys. Chem. Chem. Phys., 17 (2015) 5725-5733.

475 [16] K. Kannisto, L. Murtomaki, T. Viitala, Colloids and Surfaces B-Biointerfaces, 86 (2011) 298-304. 
[17] R. Kuldvee, M. Lindén, S. Wiedmer, M.-L. Riekkola, Anal. Bioanal. Chem., 380 (2004) 293-302.

477 [18] M.J. Blandamer, B. Briggs, P.M. Cullis, J.B.F.N. Engberts, A. Kacperska, Journal of the Chemical 478 Society, Faraday Transactions, 91 (1995) 4275-4278.

479 [19] G. McCubbin, S. Praporski, S. Piantavigna, D. Knappe, R. Hoffmann, J. Bowie, F. Separovic, L. 480 Martin, Eur Biophys J, 40 (2011) 437-446.

481

482

483

484

485 486

487

488

489

490 491

492 493

494

495

496

497

498

499

[20] J.A. Castillo, A. Pinazo, J. Carilla, M.R. Infante, M.A. Alsina, I. Haro, P. Clapés, Langmuir, 20 (2004) 3379-3387.

[21] N.-J. Cho, C.W. Frank, B. Kasemo, F. Höök, Nat. Protoc., 5 (2010) 1096-1106.

[22] K. Glasmästar, C. Larsson, F. Höök, B. Kasemo, J. Colloid Interface Sci., 246 (2002) 40-47.

[23] R.P. Richter, J. Lai Kee Him, B. Tessier, C. Tessier, A.R. Brisson, Biophys. J., 89 (2005) 33723385.

[24] K.F. Wang, R. Nagarajan, T.A. Camesano, Biophysical Chemistry, 196 (2015) 53-67.

[25] S. Heydari, G.H. Haghayegh, J. Sens. Technol., 04 (2014) 81-100.

[26] K. Kanazawa, N.-J. Cho, J. Sens., 2009 (2009) 1-17.

[27] K.F. Wang, R. Nagarajan, C.M. Mello, T.A. Camesano, J. Phys. Chem. B, 115 (2011) 1522815235.

[28] H.A. Rydberg, A. Kunze, N. Carlsson, N. Altgaerde, S. Svedhem, B. Norden, Eur. Biophys. J., 43 (2014) 241-253.

[29] C. Kataoka-Hamai, M. Higuchi, J. Phys. Chem. B, 118 (2014) 10934-10944.

[30] S.-K. Ruokonen, F. Duša, J. Lokajová, I. Kilpeläinen, A.W.T. King, S.K. Wiedmer, J. Chromatogr. A, 1405 (2015) 178-187.

[31] Y. Jing, H. Trefna, M. Persson, B. Kasemo, S. Svedhem, Soft Matter, 10 (2014) 187-195.

[32] R.P. Richter, R. Bérat, A.R. Brisson, Langmuir, 22 (2006) 3497-3505.

[33] M. Claesson, N.J. Cho, C.W. Frank, M. Andersson, Langmuir, 26 (2010) 16630-16633. 
[34] J.K. Towns, F.E. Regnier, Anal. Chem., 64 (1992) 2473-2478.

501 [35] L. Pei, C.A. Lucy, J. Chromatogr. A, 1365 (2014) 226-233.

502 [36] J. Aguiar, P. Carpena, J.A. Molina-Bolívar, C. Carnero Ruiz, J. Colloid Interface Sci., 258 (2003) 503 116-122.

504 [37] H.L. Bandey, S.J. Martin, R.W. Cernosek, A.R. Hillman, Anal. Chem., 71 (1999) 2205-2214.

505 [38] A. Gregoriades, J. Virol., 36 (1980) 470-479.

506 [39] M.V. Linden, K. Meinander, A. Helle, G. Yohannes, M.-L. Riekkola, S.J. Butcher, T. Viitala, S.K. 507 Wiedmer, Electrophoresis, 29 (2008) 852-862.

508 [40] K. Kalyanasundaram, J.K. Thomas, J. Am. Chem. Soc., 99 (1977) 2039-2044.

509 [41] M. Tariq, M.G. Freire, B. Saramago, J.A. Coutinho, J.N.C. Lopes, L.P.N. Rebelo, Chem. Soc. 510 Rev., 41 (2012) 829-868.

511 [42] D.N. LeBard, B.G. Levine, R. DeVane, W. Shinoda, M.L. Klein, Chem. Phys. Lett., 522 (2012) $51238-42$.

513 [43] T. Sakai, Y. Kaneko, K. Tsujii, Langmuir, 22 (2006) 2039-2044.

514 [44] J. Luczak, J. Hupka, J. Thoming, C. Jungnickel, Colloids Surf., A, 329 (2008) 125-133.

515 [45] M. Blesic, M.H. Marques, N.V. Plechkova, K.R. Seddon, L.P.N. Rebelo, A. Lopes, Green Chem., 5169 (2007) 481-490.

517 [46] S. Chen, S. Zhang, X. Liu, J. Wang, J. Wang, K. Dong, J. Sun, B. Xu, Phys. Chem. Chem. Phys., $51816(2014) 5893-5906$.

519 [47] B. Dong, N. Li, L. Zheng, L. Yu, T. Inoue, Langmuir, 23 (2007) 4178-4182.

520 [48] E. Ghasemian, M. Najafi, A.A. Rafati, Z. Felegari, J. Chem. Thermodyn., 42 (2010) 962-966.

521 [49] T. Viitala, J.T. Hautala, J. Vuorinen, S.K. Wiedmer, Langmuir, 23 (2007) 609-618.

522 [50] R. Richter, A. Mukhopadhyay, A. Brisson, Biophys. J., 85 (2003) 3035-3047.

523 [51] I. Reviakine, A. Brisson, Langmuir, 16 (2000) 1806-1815. 
[52] A. Kunze, S. Svedhem, B. Kasemo, Langmuir, 25 (2009) 5146-5158.

525 [53] S.-K. Mikkola, A. Robciuc, J. Lokajová, A.J. Holding, M. Lämmerhofer, I. Kilpeläinen, J.M. 526 Holopainen, A.W.T. King, S.K. Wiedmer, Environmental Science \& Technology, 49 (2015) 18705271878.

528 [54] J.E. Gómez, J.E. Sandoval, Electrophoresis, 29 (2008) 381-392.

529 [55] W.J. Lambert, D.L. Middleton, Anal. Chem., 62 (1990) 1585-1587.

530 [56] R. Haselberg, F.M. Flesch, A. Boerke, G.W. Somsen, Anal. Chim. Acta, 779 (2013) 90-95.

531 [57] N.-J. Cho, K.K. Kanazawa, J.S. Glenn, C.W. Frank, Anal. Chem., 79 (2007) 7027-7035.

532 [58] N. Granqvist, M. Yliperttula, S. Välimäki, P. Pulkkinen, H. Tenhu, T. Viitala, Langmuir, 30

533 (2014) 2799-2809.

534 [59] G.H. Zan, N.-J. Cho, Colloids Surf., B, 121 (2014) 340-346.

535 [60] A.P. Serro, A. Carapeto, G. Paiva, J.P.S. Farinha, R. Colaço, B. Saramago, Surface and Interface 536 Analysis, 44 (2012) 426-433.

537 [61] P. Losada-Pérez, M. Khorshid, C. Hermans, T. Robijns, M. Peeters, K.L. Jiménez-Monroy, L.T.N. 538 Truong, P. Wagner, Colloids Surf., B, 123 (2014) 938-944.

539 [62] N. Lu, K. Yang, B. Yuan, Y. Ma, J. Phys. Chem. B, 116 (2012) 9432-9438.

540 [63] L.M.C. Lima, M.I. Giannotti, L. Redondo-Morata, M.L.C. Vale, E.F. Marques, F. Sanz, Langmuir, $54129(2013) 9352-9361$.

542 [64] V. Arrigler, K. Kogej, J. Majhenc, S. Svetina, Langmuir, 21 (2005) 7653-7661.

543 [65] A.T. Florence, D. Attwood, Physicochemical Principles of Pharmacy, Pharmaceutical Press2006.

544 [66] J. Neugebauer, [18] Detergents: An overview, in: M. Deutscher (Ed.) Guide to Protein 545 Purification, Academic Press1990, pp. 239-253.

546 [67] A.S. Wells, V.T. Coombe, Org. Process Res. Dev., 10 (2006) 794-798. 
$548 \quad$ Figures captions

549 Figure 1. Structure of ionic liquids: A) $\left[\mathrm{P}_{8444}\right] \mathrm{Cl}$ and B) $\left[\mathrm{P}_{14444}\right] \mathrm{Cl}$.

550

551 Figure 2. Surface tension of increasing concentration of $\left[\mathrm{P}_{8444}\right] \mathrm{Cl}$ in water $(\circ)$ and in sodium phosphate 552 buffer ( $\square$ ) measured using the optical pendant drop method.

553

554 Figure 3. A) CMC determinations of $\left[\mathrm{P}_{14444}\right] \mathrm{Cl}$ in water $(\circ)$ and in sodium phosphate buffer $(\Delta)$ using 555 fluorescence spectroscopy (full symbols) and surface tension (empty symbols). Left y axis shows 556 intensity ratios of the first and third vibronic peak $\left(\mathrm{I}_{1} / \mathrm{I}_{3}\right)$ located at 370 and $380 \mathrm{~nm}$, respectively. 557 B) Corresponding fluorescence emission spectra of $1 \mu \mathrm{M}$ pyrene in the presence of increasing 558 concentrations of $\left[\mathrm{P}_{14444}\right] \mathrm{Cl}$ in water solution.

559

560 Figure 4. QCM graphs of normalized overtone frequencies (3rd, 5th, 7th, 9th) and modeled thickness of 561 liposome layers for three subsequent runs ( $1^{\text {st }}$ empty, $2^{\text {nd }}$ half-filled, and $3^{\text {rd }}$ full symbol $)$ for $\left.A\right)\left[\mathrm{P}_{8444}\right] \mathrm{Cl}$ 562 addition to liposomes adhered on a polybrene coated crystal; B) $\left[\mathrm{P}_{14444}\right] \mathrm{Cl}$ addition to liposomes adhered 563 on a polybrene coated crystal. Sensor pretreatment (400 second steps): water, $0.1 \mathrm{mM} \mathrm{NaOH,} \mathrm{water,} 1 \%$ $564(w / w)$ polybrene, water. Measurement sequence: A: sodium phosphate buffer (100 s), EggPC/POPG 565 (200 s), sodium phosphate buffer (400 s), $2.8 \cdot 10^{-3} \mathrm{mM}\left[\mathrm{P}_{8444}\right] \mathrm{Cl}(400 \mathrm{~s}), 2.8 \cdot 10^{-2} \mathrm{mM}\left[\mathrm{P}_{8444}\right] \mathrm{Cl}(400 \mathrm{~s})$, $5662.8 \cdot 10^{-1} \mathrm{mM}\left[\mathrm{P}_{8444}\right] \mathrm{Cl}(600 \mathrm{~s}), 2.8 \mathrm{mM}\left[\mathrm{P}_{8444}\right] \mathrm{Cl}(600 \mathrm{~s}), 28 \mathrm{mM}\left[\mathrm{P}_{8444}\right] \mathrm{Cl}$ (600 s), sodium phosphate 567 buffer (600 s). B: sodium phosphate buffer (100 s), EggPC/POPG (200 s), sodium phosphate buffer $568(400 \mathrm{~s}), 2.3 \cdot 10^{-3} \mathrm{mM}\left[\mathrm{P}_{14444}\right] \mathrm{Cl}(400 \mathrm{~s}), 2.3 \cdot 10^{-2} \mathrm{mM}\left[\mathrm{P}_{14444}\right] \mathrm{Cl}(600 \mathrm{~s}), 2.3 \cdot 10^{-1} \mathrm{mM}\left[\mathrm{P}_{14444}\right] \mathrm{Cl}(800 \mathrm{~s})$, $5692.3 \mathrm{mM}\left[\mathrm{P}_{14444}\right] \mathrm{Cl}(800 \mathrm{~s})$, sodium phosphate buffer $(600 \mathrm{~s})$ 570 
571 Figure 5. A) Change of relaxation time of adsorbed liposomes versus increasing concentration of $572\left[\mathrm{P}_{8444}\right] \mathrm{Cl}$; B) Change of relaxation time of adsorbed liposomes premixed with $0.28 \mathrm{mM}\left[\mathrm{P}_{8444}\right] \mathrm{Cl}$ (middle 573 point showing mean value of two measurements which are designated by the ends of error bars)

574

575 Figure 6. A) Change of relaxation time of adsorbed liposomes versus increasing concentration of $576\left[\mathrm{P}_{14444}\right] \mathrm{Cl}$; B) Change of relaxation time of adsorbed liposomes premixed with $0.28 \mathrm{mM}\left[\mathrm{P}_{14444}\right] \mathrm{Cl}$ 577 (middle point showing mean value of two measurements and ends of error bars are the actual measured 578 values)

579

580 Figure 7. QCM graphs of normalized overtone frequencies (3rd, 5th, 7th, and 9th) and modeled thickness 581 of liposome layers for three subsequent runs for $\mathrm{A})\left[\mathrm{P}_{8444}\right] \mathrm{Cl}$ and liposomes premixed system washing of 582 the polybrene coated crystal; B) $\left[\mathrm{P}_{14444}\right] \mathrm{Cl}$ and liposomes premixed system washing of the polybrene 583 coated crystal. Sensor pretreatment (400 second steps): water, $0.1 \mathrm{mM} \mathrm{NaOH}$, water, $1 \%(w / w)$ 584 polybrene, water. Measurement sequence: A) sodium phosphate buffer (60 s), EggPC/POPG + $5852.8 \cdot 10^{-2} \mathrm{mM}\left[\mathrm{P}_{8444}\right] \mathrm{Cl}(600 \mathrm{~s})$, sodium phosphate buffer (1000 s). B) sodium phosphate buffer (60 s), 586 EggPC/POPG $+2.3 \cdot 10^{-2} \mathrm{mM}\left[\mathrm{P}_{14444}\right] \mathrm{Cl}(600 \mathrm{~s})$, sodium phosphate buffer $(600 \mathrm{~s})$ 


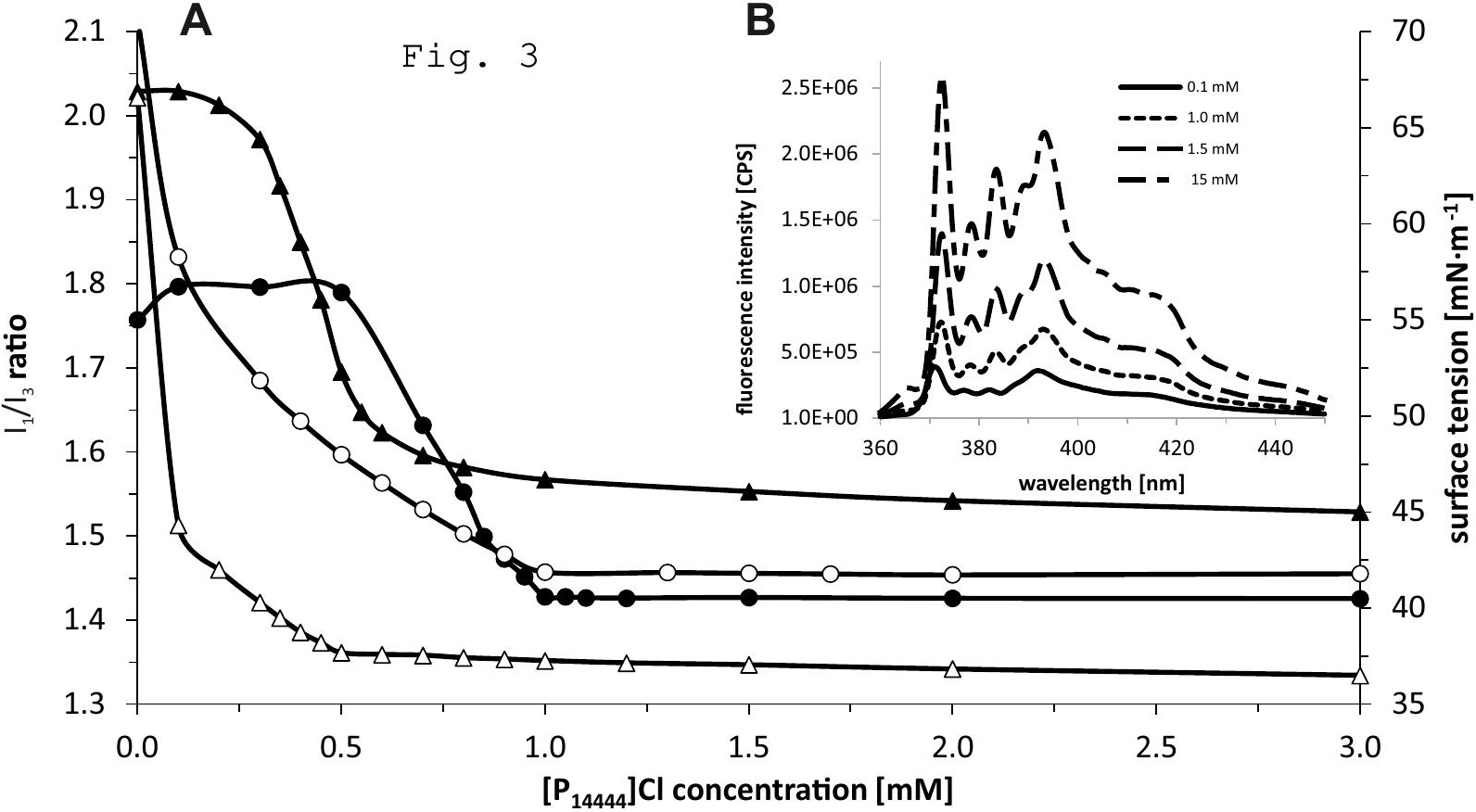

B 


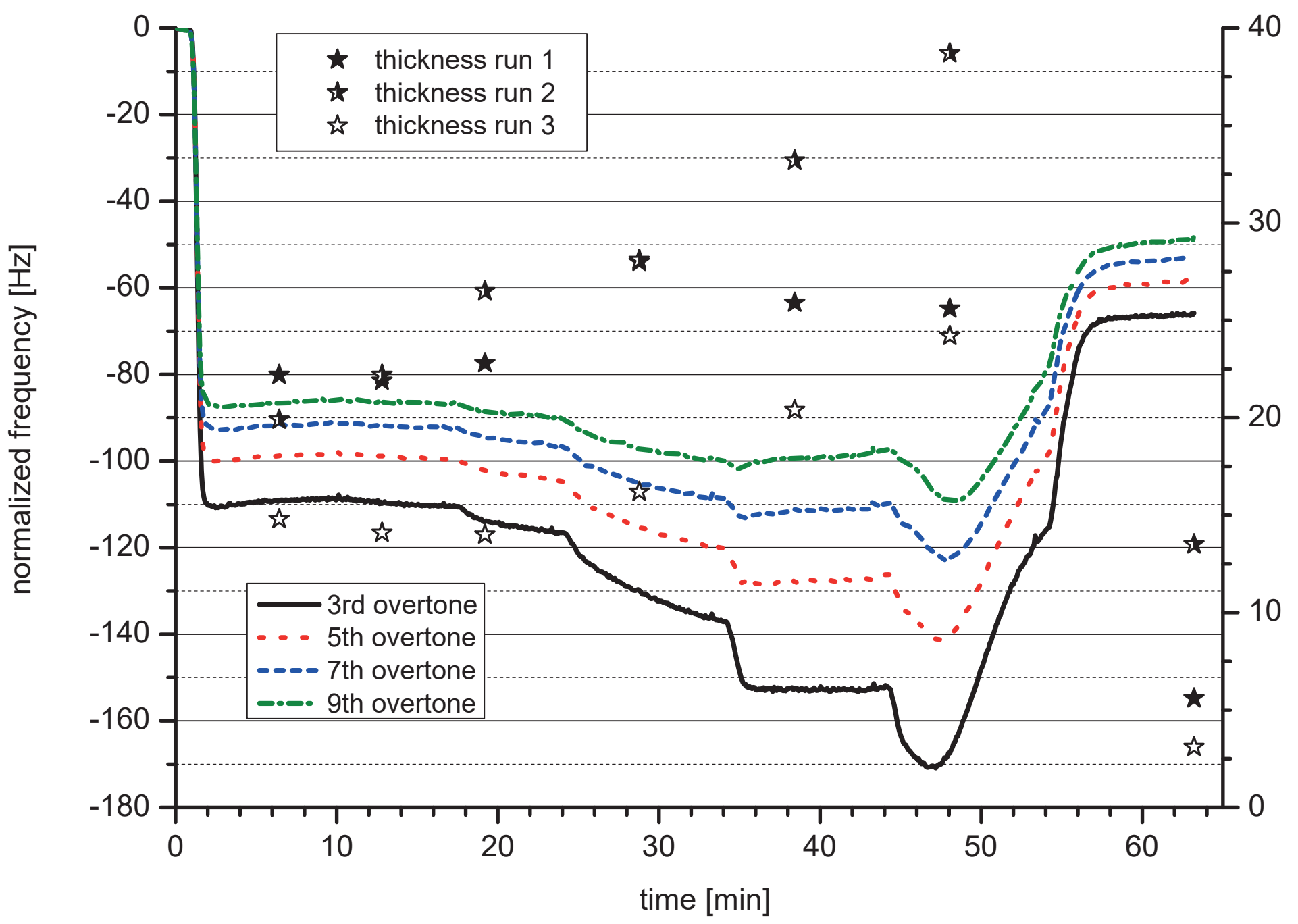

B

$\left[\mathrm{P}_{14444}\right] \mathrm{Cl} \mathrm{QCM}$ analysis
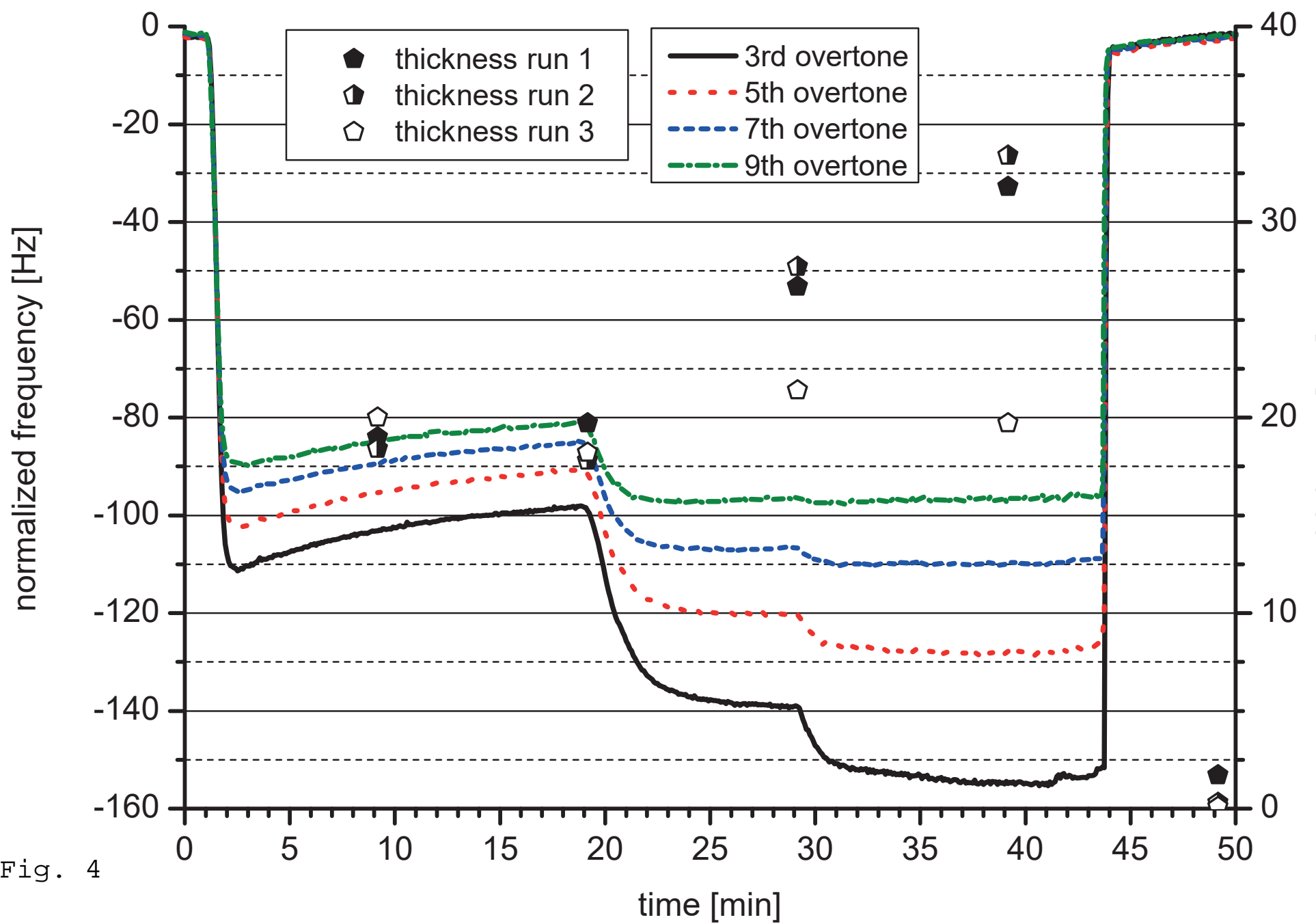


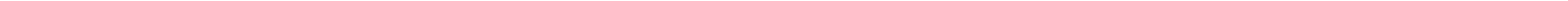


Liposomes $+\left[\mathrm{P}_{8444}\right] \mathrm{Cl}$ premixed system QCM analysis

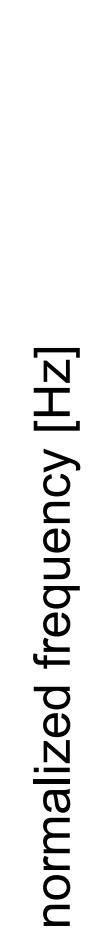

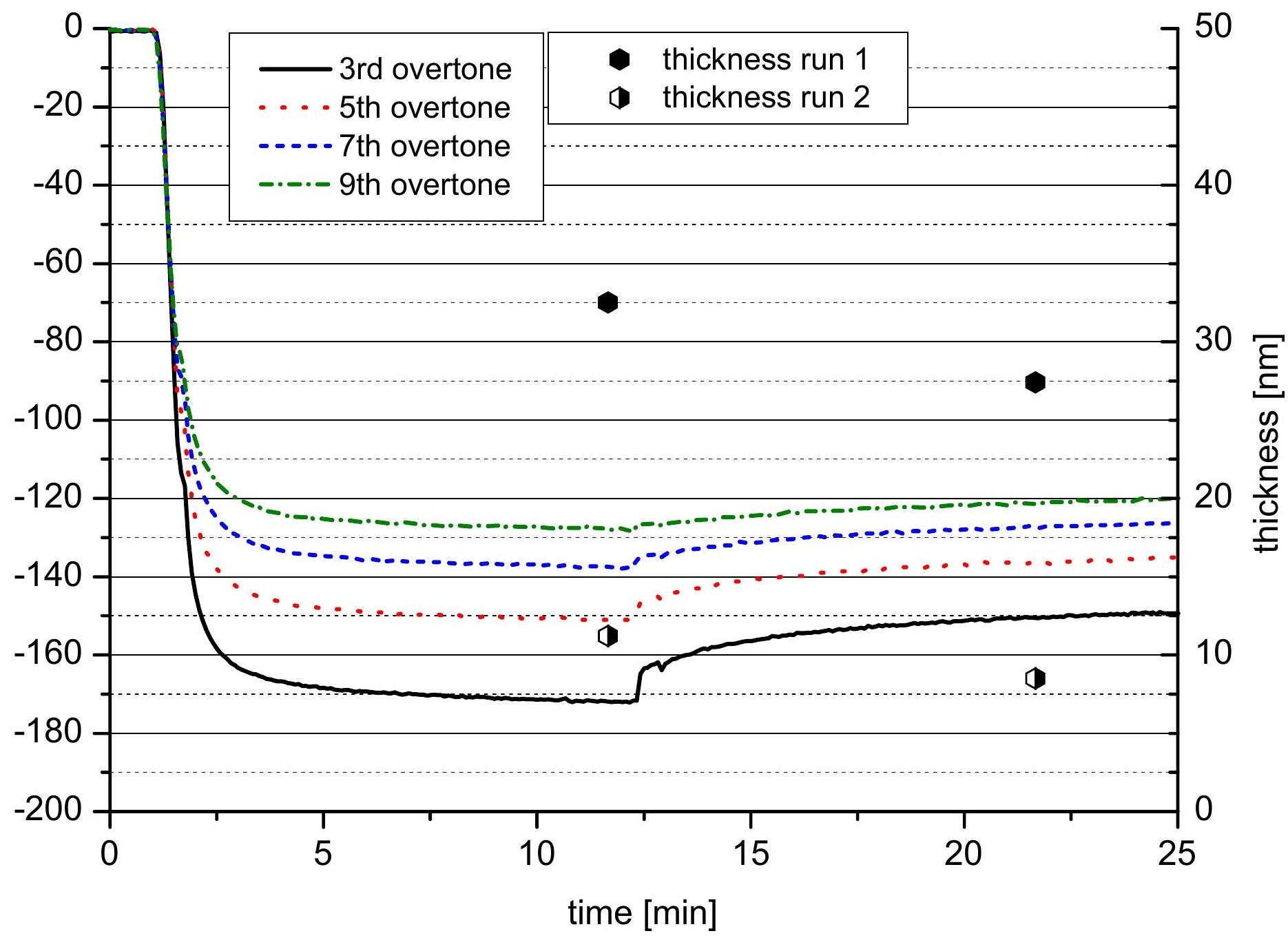

Liposomes $+\left[\mathrm{P}_{14444}\right] \mathrm{Cl}$ premixed system QCM analysis
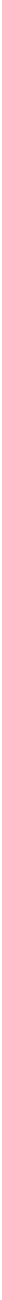